\title{
Cardiovascular Involvement in COVID-19: What Sequelae Should We Expect?
}

\author{
Maria Vincenza Polito · Angelo Silverio · Michele Bellino · \\ Giuseppe Iuliano - Marco Di Maio • Carmine Alfano • Patrizia Iannece • \\ Nicolino Esposito · Gennaro Galasso
}

Received: May 10, 2021 / Published online: June 30, 2021

(C) The Author(s) 2021

\section{ABSTRACT}

Several forms of cardiovascular involvement have been described in patients with Coronavirus disease 19 (COVID-19): myocardial injury, acute coronary syndrome, acute heart failure, myocarditis, pericardial diseases, arrhythmias, takotsubo syndrome, and arterial and venous atherothrombotic and thromboembolic events. Data on long-term outcome of these patients are still sparse, and the type and real incidence of cardiovascular sequelae are poorly known. It is plausible that myocardial injury may be the initiator of an inflammatory cascade, edema, and subsequent fibrosis, but also a consequence of systemic inflammation. The extent and distribution of ongoing inflammation may be the basis for ventricular dysfunction and malignant arrhythmias. Indeed, preliminary observational findings seem to emphasize the importance of

M. V. Polito · N. Esposito

Department of Cardiology, Ospedale Evangelico

Betania, Naples, Italy

A. Silverio $(\varangle) \cdot$ M. Bellino $\cdot$ G. Iuliano ·

M. Di Maio - C. Alfano - G. Galasso

Department of Medicine, Surgery and Dentistry,

University of Salerno, Baronissi, Salerno, Italy

e-mail: asilverio@unisa.it

P. Iannece

Department of Chemistry and Biology, University of

Salerno, Fisciano, Italy close monitoring of COVID-19 patients with myocardial injury after discharge. Residual subclinical disease may be effectively investigated by using second-level imaging modalities such as cardiac magnetic resonance, which allows better characterization of the type and extension of myocardial damage, as well as of the ongoing inflammation after the acute phase. In patients with venous thromboembolism, a very common complication of COVID-19, the type and the duration of anticoagulation therapy after the acute phase should be tailored to the patient and based on the estimation of the individual thromboembolic and hemorrhagic risk. Large randomized clinical trials are ongoing to address this clinical question. Whether the severity of cardiovascular involvement, the type of treatments adopted during the acute phase, and the hemodynamic response, may influence the long-term outcome of patients recovered from COVID-19 is unknown. An etiological diagnosis of myocardial injury during the hospitalization is the first step for an appropriate follow-up in these patients. After discharge, the screening for residual left and right ventricular dysfunction, arrhythmias, residual thrombosis, and myocardial scar should be considered on a case-by-case basis, whereas an active clinical surveillance is mandatory in any patient. 
Keywords: COVID-19;

SARS-CoV-2;

Coronavirus; Myocarditis; Acute coronary syndromes; Myocardial injury; Pericarditis; Pulmonary embolism; Long-term outcome

\section{Key Summary Points}

Coronavirus disease 2019 (COVID-19) may deteriorate the clinical status of subjects with underlying cardiovascular (CV) diseases and cause several de novo CV complications, including heart failure, myocardial infarction, myocarditis, takotsubo syndrome, life-threatening arrhythmias, and thromboembolic events.

Persistent subclinical cardiac damage after COVID-19 resolution has been reported, but whether this finding may affect longterm outcome is still poorly understood.

Myocardial tissue fibrosis and ongoing inflammation, mediated by several mechanisms, may be responsible for ventricular dysfunction and arrhythmias during follow-up.

Correct etiologic diagnosis of myocardial injury during hospitalization may allow for more proper therapeutic and follow-up strategies including second-level imaging modalities. After the acute phase, active surveillance is mandatory in any patient.

Although difficult to routinely perform after COVID-19 recovery, cardiac magnetic resonance should be considered in subjects with high clinical probability of cardiovascular sequelae at follow-up.

\section{INTRODUCTION}

Severe acute respiratory syndrome coronavirus 2 (SARS-CoV-2) is a human beta coronavirus, discovered for the first time in Wuhan, China, in December 2019, and recognized as the cause of the coronavirus disease 2019 (COVID-19) [1].
This represents a public health emergency of pandemic proportions, being responsible for high rates of morbidity and mortality worldwide [2].

COVID-19 is characterized by a wide spectrum of possible clinical presentations, ranging from asymptomatic forms to severe respiratory failure, multi-organ damage, and death. Most people with SARS-CoV-2 infection are minimally symptomatic, but approximately onefifth require hospitalization and may develop severe disease.

Although pneumonia is the most common clinical manifestation of SARS-CoV-2, COVID19 may affect all organs, structurally and functionally, and precipitate a variety of systemic complications involving kidneys, gut, and cardiovascular (CV) apparatus [3].

A potential explanation must be searched in angiotensin-converting enzyme 2 (ACE2), a surface molecule that mediates the virus entry into the cells through the interaction with the viral spike protein [4]. ACE2 is expressed in a variety of cells including pneumocytes, macrophages, enterocytes, cardiac myocytes, pericytes, and endothelial cells [5].

COVID-19 may deteriorate the clinical status of subjects with underlying CV diseases, reported in approximately $20 \%$ of the patients, and cause de novo CV complications [6-8]. Several forms of $\mathrm{CV}$ involvement have been described: myocardial injury, acute coronary syndrome (ACS), exacerbation of heart failure (HF), myocarditis-like syndrome, pericardial diseases, arrhythmias, takotsubo syndrome, and arterial and venous atherothrombotic and thromboembolic events (Fig. 1).

For these conditions, several mechanisms have been postulated: oxygen supply/demand imbalance due to the hypoxic state, local and systemic inflammatory response with cytokinemediated injury, virus-mediated cellular damage, endothelial injury, plaque instability, and prothrombotic status. Alone or in combination, these conditions may be responsible for sequelae and CV adverse events after the infection resolution, and affect patients' outcomes in the short and long term. Indeed, as the COVID-19 pandemic has progressed, several cases of patients with persistent symptoms or 


\section{CARDIOVASCULAR INVOLVEMENT IN COVID-19}

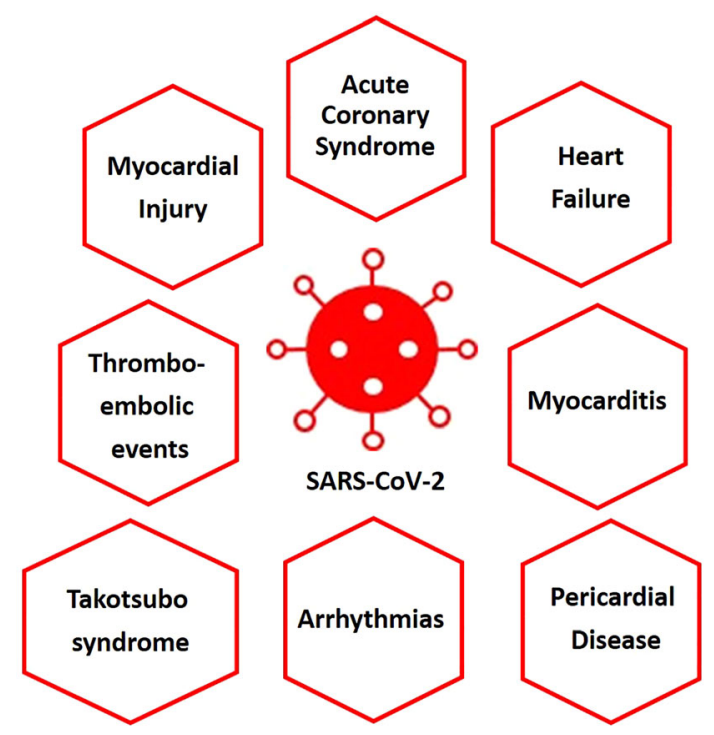

Fig. 1 Cardiovascular involvement by SARS-CoV-2

complications occurred after the end of the acute phase of the disease have been reported. Owing to the potential clinical implications of this so-called "long COVID" or "post-COVID-19 syndrome", the National Institute for Health and Care Excellence in partnership with the Scottish Intercollegiate Guidelines Network and the Royal College of General Practitioners have published guidelines for clinicians on the management and care of people with long-term effects of COVID-19 $[9,10]$. Many other health societies and institutions around the world are involved in the development of shared documents for the management of this huge number of subjects.

In a recent Italian study, 143 patients with recent SARS-CoV-2 infection were enrolled after testing negative with nasopharyngeal swab [11]. Data about the persistence of specific symptoms potentially correlated with COVID-19 were obtained using a standardized questionnaire administered at enrollment. Patients were assessed at a mean of 60 days after onset of the first COVID-19 symptoms; at the time of the evaluation, only $13 \%$ were completely free from any COVID19-related symptom, while $32 \%$ had one or two symptoms, and 55\% had three or more symptoms. A worsened quality of life was observed among $44 \%$ of the patients. Symptoms most reported were fatigue $(53 \%)$, dyspnea $(43 \%)$, joint pain $(27 \%)$, and chest pain $(22 \%)$.

Previous clinical studies on patients with pneumonia have documented a two- to eightfold increase in the risk of $\mathrm{CV}$ diseases within the first 30 days from hospitalization; this risk remained high even up to 10 years [12]. The highest probability to develop adverse $\mathrm{CV}$ events was observed during the first years, independently from the severity of the respiratory infection [13].

A retrospective cohort study including 47,780 COVID-19 individuals discharged alive from the hospital showed a high incidence of new-onset multiorgan dysfunction and the occurrence of $\mathrm{CV}$ events [composite of $\mathrm{HF}$, myocardial infarction (MI), stroke, and arrhythmia] three times more frequently than in the matched control group at a mean followup time of 140 days [14].

These data, along with the uncertainty about the course of the disease, emphasize the importance of close monitoring of patients who recovered, either partially or completely, from COVID-19. To date, the need of long-term outcome data remains unaddressed, and the type and real incidence of CV sequelae after COVID19 is poorly known. This article is based on previously conducted studies and does not contain any new studies with human participants or animals performed by any of the authors.

\section{Myocardial Injury}

Myocardial injury, defined as increased serum troponin levels about 99th percentile of upper reference limit, has been reported in up to $20-30 \%$ of the patients hospitalized with COVID-19 at the time of admission or during hospitalization. Multiple mechanisms potentially responsible for myocardial injury, alone or in combination, have been advocated: hypoxemia, endothelial dysfunction, cytokine storm, and direct virus-mediated damage. These factors may induce diffuse myocardial tissue inflammation, endothelial injury, and plaque instability, which favor procoagulant status and 
micro-and macro-vascular dysfunction (Fig. 2) [15]. Patients with myocardial injury were generally older, with a higher prevalence of hypertension, diabetes, coronary artery disease (CAD) and HF [16]. Acute myocardial injury has been associated with a higher risk of ventricular arrhythmias, acute respiratory and kidney failure, coagulation disorders, higher inflammatory biomarkers and, eventually, a higher rate of inhospital mortality $[17,18]$. In the study by Yang et al., myocardial injury was significantly prevalent among critically ill patients $(47 \%)$ as compared to those moderately ill (12\%) upon admission, and in non-survivors (50\%) as compared to survivors (6\%) [19].

Of note, COVID-19 patients were frequently found without obstructive epicardial CAD on coronary angiography [20], and showed impairment of left ventricular myocardial contractility by 2-D speckle-tracking echocardiography mainly in the subepicardial than in the subendocardial layers [21]. This supports the hypothesis of inflammation-mediated damage beyond ischemia.

The long-term outcomes among hospitalized patients with myocardial injury, type $1 \mathrm{MI}$ and type $2 \mathrm{MI}$, have been widely investigated in previous studies [22]. At 5 years, Chapman and colleagues reported a higher rate of all-cause death in patients with myocardial injury (72.4\%) or type $2 \mathrm{MI}(62.5 \%)$ as compared to those with type $1 \mathrm{MI}(36.7 \%)$ [23]. Patients with myocardial injury or type $2 \mathrm{MI}$ had a higher risk of major adverse cardiovascular events (RR, 1.56; 95\% CI 1.29-1.88) compared to patients with type $1 \mathrm{MI}$. These data may be relevant for patients that have recovered from COVID-19 and cardiac injury at hospitalization, especially for those with post-COVID syndrome and/or

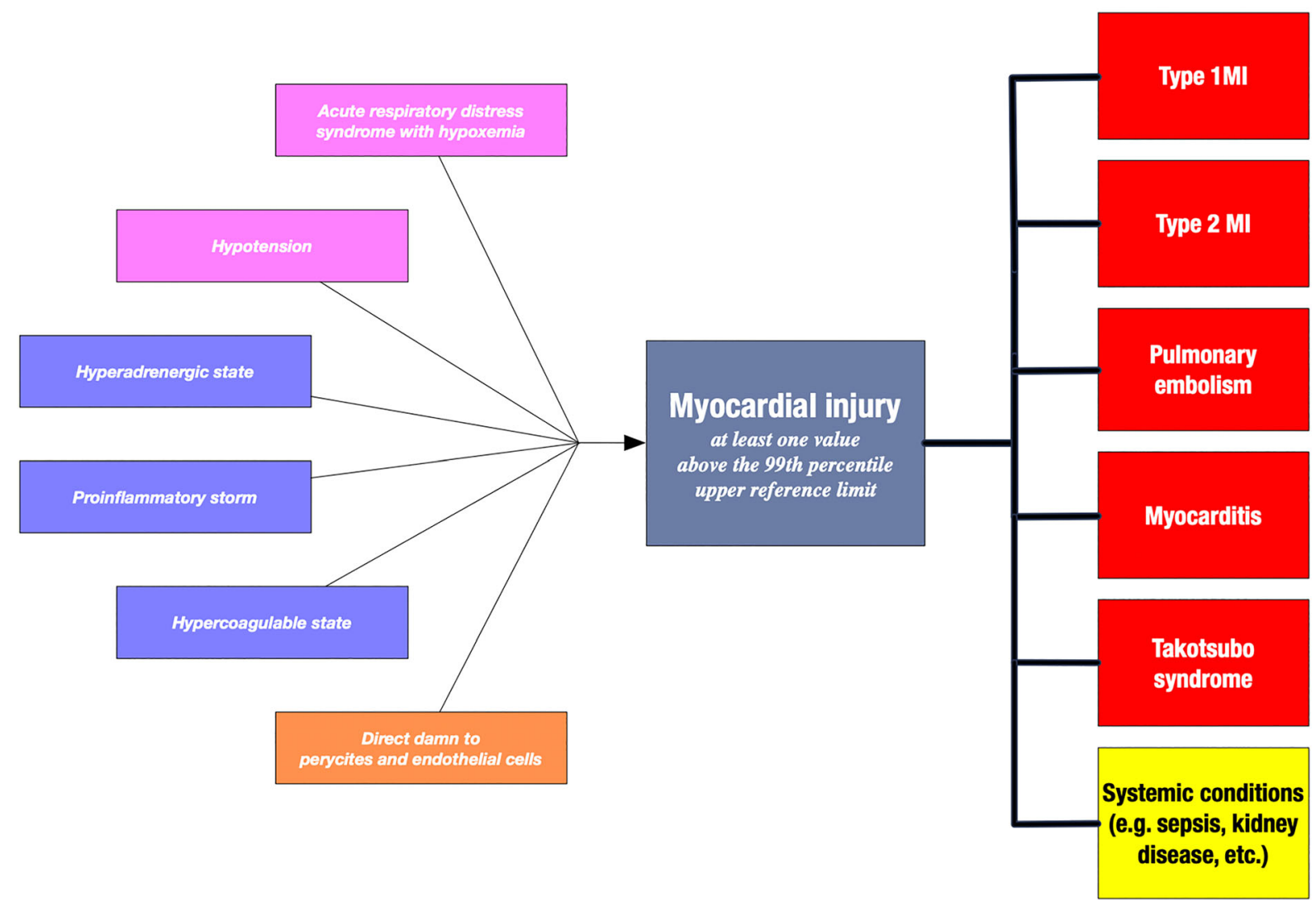

Fig. 2 Pathophysiology of myocardial injury during acute SARS-CoV-2 infection and potential long-term sequelae following the recovery. $M I$ myocardial infarction 
imaging evidence of persistent myocardial damage.

Cardiac magnetic resonance (CMR) has the unique ability to identify non-invasively the inflammatory damage of myocardium, in localizing the sites of inflammation or fibrosis, and in assessing the presence and severity of functional impairment [24-26]. Recent CMR studies have shown that ongoing inflammation and residual fibrosis may be detected after COVID-19 resolution and subclinical myocardial abnormalities are still detectable several months after recovery.

Puntmann et al. published a prospective observational study showing a high percentage of abnormal CMR findings in recently recovered COVID-19 patients [22]. Furthermore, in a multicenter study including 148 patients with COVID-19 and elevated serum troponin levels at admission at six hospitals, CMR showed myocardial damage in approximately half of the patients up to 3 months from discharge [27]. Myocarditis-pattern injury was observed in $27 \%$ of cases, ischemic pattern in $22 \%$, and nonspecific LGE in 5\% of patients. Combined ischemic and non-ischemic late gadolinium enhancement (LGE) was detected in 6\% of cases. Interestingly, in patients with myocarditis-like scar, biventricular function was preserved and ongoing active myocardial inflammation was also described in a significant percentage of cases.

Whether these findings may influence the patient's clinical status and outcome is currently unknown and is the subject of ongoing studies [28]. Another issue is the identification and implementation of effective therapies during the hospitalization of patients with myocardial injury, taking into account the long-term inflammatory and fibrotic sequelae as measures of treatment effect.

Waiting for evidence from literature, patients with myocardial injury during the hospitalization should be referred for a dedicated cardiology follow-up program including the use of second-level CV imaging modalities.

\section{Acute Coronary Syndrome}

SARS-CoV-2 has also been considered a potential causative agent of ACS. The macrophage hyperactivation, with collagenases secretion, and subsequent degradation of the atheromasic fibrous cap, may favor coronary plaque rupture [29]. Furthermore, the systemic inflammatory response of COVID-19 may cause a hyperadrenergic condition and augmented cardiac work secondary to tachycardia. These conditions, associated with a hypercoagulable state and endothelial inflammation, are considered the key players of plaque instability and thrombosis involved in type $1 \mathrm{MI}$. On the other hand, the hypoxemia secondary to COVID-19related pulmonary involvement might favor the imbalance of myocardial oxygen supply/demand and lead to type 2 MI. Vasospasm and coronary artery dissection have also been described in the pathogenesis of ACS in COVID19 [30, 31].

In a preliminary series of 18 patients with COVID-19 and ST-segment elevation, potentially related to MI, nine patients underwent coronary angiography and only six were diagnosed with obstructive coronary disease. Of these, five underwent percutaneous coronary intervention (PCI) and one was treated with fibrinolytic agents. In the remaining cases, despite the absence of coronary angiography, myocardial injury secondary to microvascular dysfunction was hypothesized [32].

Stefanini et al., in an Italian multicenter series of 28 COVID-19 patients with ST-segment elevation MI (STEMI), reported ST-segment elevation as the first sign of COVID-19 syndrome in 24 patients and the angiographic evidence of an infarct-related lesions requiring revascularization in 17 cases $(60.7 \%)$ [33].

Notably, despite the demonstrated association between ACS and COVID-19, a reduction in PCI rate for ACS has been reported in different countries, including the US, Italy, and Spain $(38,32$, and $40 \%$, respectively) during the peak of the pandemic $[34,35]$. These findings were consistent with an extensive global survey by the European Society of Cardiology involving 141 countries and 3101 cardiologists that showed a reduction of hospitalization for 
MI $>50 \%$ [36]. Similarly, the ISACS-STEMI COVID-19 registry, which enrolled 6609 patients undergoing primary PCI in 77 centers located in 18 countries, showed a significant reduction in primary PCI procedures compared with 2019 (incidence rate ratio: 0.811; 95\% confidence interval: 0.78 to $0.84 ; p<0.001$ ). Furthermore, the COVID-19 outbreak was associated with significantly increased door-toballoon and total ischemia times, and these data could explain the increased mortality observed during the pandemic as compared to the past years. The potential reasons may be different, including the overwhelmed healthcare assistance and the lower rate of ACS hospital admission secondary to fear of infection [37]. At the same time, the incidence of out-ofhospital cardiac arrest markedly increased during the pandemic in Italy, being strongly associated with the cumulative incidence of COVID19 cases [38].

In a previous study on 100 patients hospitalized for COVID-19, 78 showed cardiac involvement at CMR and $12 \%$ had an ischemictype pattern of myocardial LGE [22]. Furthermore, in the subgroup with CAD, increased native $\mathrm{T} 1$ measures were strongly associated with worse CV outcomes.

In the study by Kotecha et al., two-thirds of the patients that recovered from SARS-CoV-2 infection showed signs of myocardial ischemia by CMR, albeit in absence of a previous history of CAD [27]. Interestingly, seven out of 148 patients with evidence of MI had also additional inducible ischemia on adenosine stress and 13 inducible ischemia without evidence of MI. This suggests that COVID-19 patients with myocardial injury or MI during the hospitalization who did not undergo coronary angiography should be evaluated for their CAD pre-test probability to identify those requiring further investigations with non-invasive and invasive techniques.

Among the long-term $\mathrm{CV}$ sequelae of $\mathrm{MI}$ in COVID-19, a higher rate of uncommon postinfarction mechanical complications is expected as a consequence of delaying or not performing any revascularization procedures in patients with clinical evidence of MI [39]. Pilato et al., in an Italian single-center experience, reported an increase of left ventricular free-wall rupture from one case per year to five cases in only 2 months during the COVID-19 pandemic [40]. Similarly, a high number of left ventricular (LV) pseudoaneurysms that could also develop after weeks or months after MI has been reported [41]. Moreover, LV adverse remodeling, increased diastolic filling pressures, and moderate-to-severe functional mitral regurgitation could all be potential long-term consequences of MI underdiagnosis and undertreatment during COVID-19 pandemic and may evolve toward $\mathrm{HF}$.

The occurrence of MI in patients with COVID-19 as well as the delay/underdiagnosis in the pandemic context may have a terrifying impact on the number of patients with HF with reduced ejection fraction (EF) and arrythmias in the next months. Unfortunately, these data are still poorly available, and dedicated studies are strongly needed to plan adequate healthcare strategies.

\section{Myocarditis}

Myocardial cells are a potential target of SARSCoV-2. Coronavirus-related myocarditis has been reported in several single reports or small series. In most cases, the diagnosis was formulated as "clinically suspected" on the basis of cardiac biomarkers, combined with electrocardiographic and echocardiographic data [42]. Although considered the gold standard to verify the diagnosis of "clinically suspected myocarditis", to characterize the infiltrates and understand the underlying mechanisms at the cellular level, CMR and endomyocardial biopsy (EMB) have been seldomly performed [43]. Therefore, despite the description of several clinical-based "myocarditis-like syndromes", the real incidence of proven COVID-19-related myocarditis may be under- or overestimated [44].

In the work by Kawakami et al., the results of prior studies published on 201 EMB samples in the setting of COVID-19 infection were shown. The investigators found evidence of myocarditis of unclear extent and nature in only $4.5 \%$ of cases [45]. 
In contrast with histopathological findings from lung specimens, SARS-CoV-2 RNA was not found in the cardiomyocytes. Inflammatory mononuclear infiltrate in autoptic hearts was recognized, but without evidence of direct virus replication in the myocardium [46]. This evidence suggests that myocarditis may be caused by an indirect damage related to the cytokine storm rather than a direct SARS-CoV-2-mediated cellular effect.

Three systematic reviews have summarized the cases of COVID-19-induced myocarditis reported so far in order to describe the main clinical characteristics, diagnostic work-up, and outcome [47-49]. Interestingly, in the metasummary by Ho et al., only 12 cases were diagnosed by CMR or histopathology while the diagnosis of 39 cases of "reported" myocarditis were based on cardiac biomarkers, electrocardiograms, and/or echocardiograms. These patients were mostly young (median age 55 years), male $(69 \%)$, without CV comorbidities, and reported fever as the most common clinical presentation. The only outcome data available referred to the in-hospital course; two patients died whereas the others recovered and were discharged. These observations support a favorable in-hospital course, although the limited number of cases does not allow for definitive conclusions.

Conversely, follow-up data are really poor and the long-term consequences of recovered SARS-CoV-2-related myocarditis are still unknown [50]. The clinical picture of viral myocarditis varies from asymptomatic or paucisymptomatic forms to acute $\mathrm{HF}$, pulmonary edema, cardiogenic shock, and/or life-threatening arrhythmias. After resolution, post-viral cardiomyopathy with persistently reduced or worsening EF may develop, usually within 6 to 12 months [51]. It is reasonable to think that SARS-CoV-2-associated myocarditis may also cause the same CV sequelae in the long term, thus leading to an augmented risk of $\mathrm{HF}$, arrhythmic burden, and sudden cardiac death, especially in the presence of residual inflammation and LGE at CMR [52-56]. However, the "myocarditis-like syndrome" related to COVID-
19 seems to be related to indirect myocardial damage rather than direct virus-mediated myocardial cell injury, and its long-term outcome may be more favorable than expected.

In one series of patients recovered from COVID-19 and reporting symptoms suggestive for cardiac involvement, CMR showed myocardial edema and/or foci of LGE as well as impaired right ventricular function (RV) in a significant percentage of cases [57].

In the study by Puntmann et al., ongoing myocardial inflammation was found in $60 \%$ of patients, regardless of preexisting conditions, severity and in-hospital course, and time from COVID-19 diagnosis [22]. Moreover, compared to the control group, the patients that recovered from COVID-19 had lower LV EF, higher LV volumes and LV mass, raised T1- and T2weighted images, as well as more frequent LGE or pericardial enhancement. These preliminary studies seem to support the possibility that, even months after infection, chronic myocardial inflammation persists and ventricular dysfunction may occur (Table 1).

Since subclinical persistent myocardial involvement after COVID-19 resolution has the potential to precipitate arrhythmias and sudden cardiac death during moderate-to-high intensity physical activity, medical concern has already been raised in the athletic community. During 2020, due to the growing acknowledgment of COVID-19-induced cardiac injury in professional athletes and raising evidence suggesting higher-than-expected incidences of myocardial inflammation in recovered nonathletic but also in athletic population, several return-to-play recommendations for previously infected athletes were published [22, 58-61]. Current recommendations suggest a prudent exclusion of complications with a combination of ECG, biomarkers, and echocardiography [62-64]. Further examinations including CMR, computed tomography, stress echocardiography/cardiopulmonary exercise testing, and nuclear/positron emission tomography should be performed in the presence of persistent or new-onset CV symptoms [64]. 
Table 1 In-hospital and potential late sequelae in COVID-19 patients with myocarditis

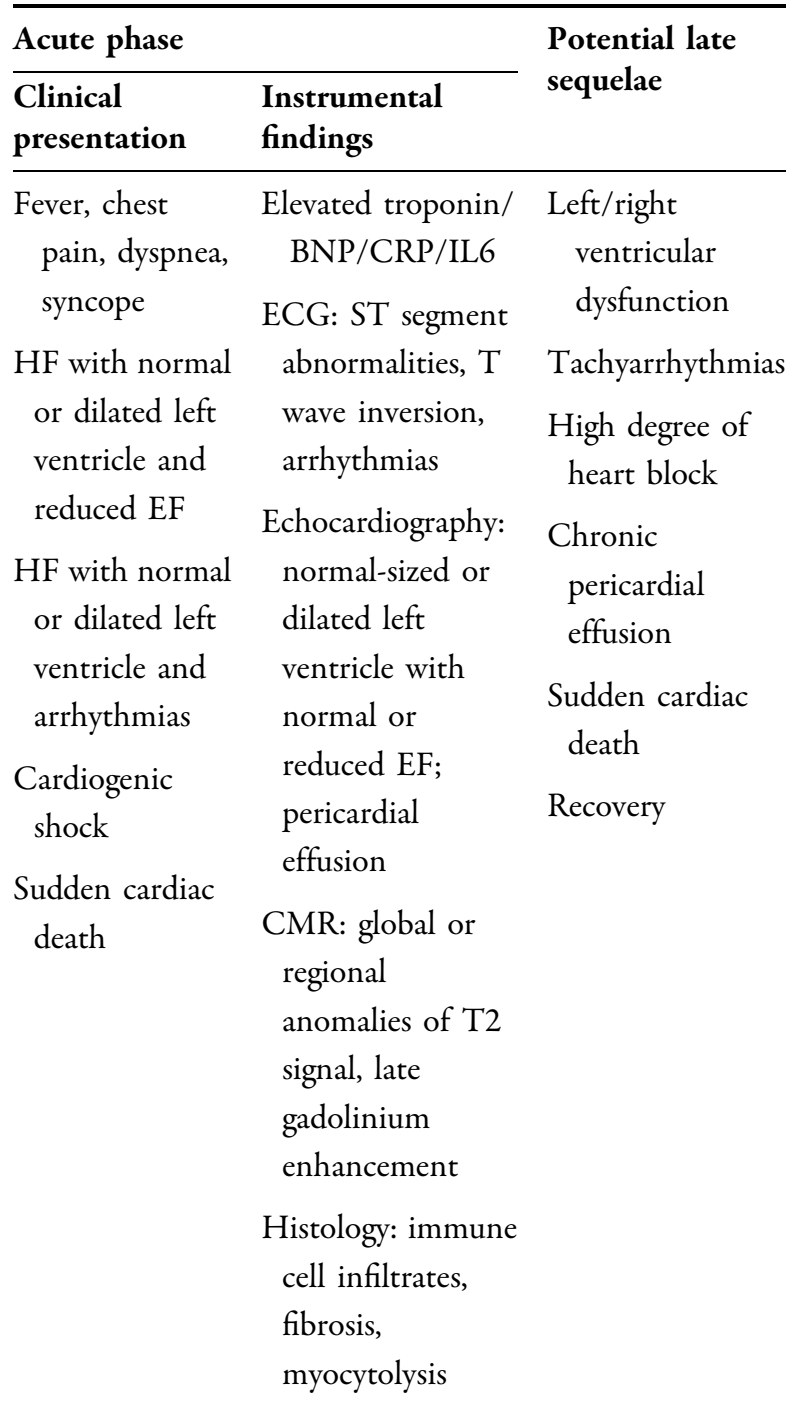

$E F$ ejection fraction, $B N P$ brain natriuretic peptide, $C M R$ cardiac magnetic resonance, $C R P \mathrm{C}$ reactive protein, $E C G$ electrocardiogram, $H F$ heart failure, IL6 interleukin 6

The best follow-up strategy and secondary preventive treatment after COVID-19-myocarditis is currently unknown, and a careful assessment on a case-by-case basis is highly advisable.

\section{Pericardial Diseases}

Viral pathogens are involved in pericarditis etiopathogenesis and, generally, they have a benign clinical course. Only case reports have been published on pericardial involvement in COVID-19, namely acute pericarditis, cardiac tamponade, or pericardial effusion, with or without myocardial involvement. Sometimes pericarditis may be the primary presentation of SARS-COV-2 infection, even in the absence of clear respiratory tract symptoms and/or other systemic complications. The clinical expression varies from minimal pericardial swelling to severe effusion, potentially evolving toward cardiac tamponade [65]. It has been hypothesized that pericardial inflammation may depend on cytotoxic or immune-mediated effect of virus rather than from direct viral damage. However, the mechanisms are not completely elucidated, as well as the long-term clinical consequences.

In a small series of patients with myocarditislike syndrome by COVID-19 referred for CMR, a mild pericardial effusion was reported in $75 \%$ of cases without evidence of pericardial thickening [66]. Similarly, in 16 COVID-19 autopsy cases, pericardial effusion was found in almost all cases (94\%), although generally mild (estimated from 50 to $100 \mathrm{ml}$ ) [45]. In about $20 \%$ of patients recently recovered from COVID-19 infection, emerging CMR data have shown pericardial involvement with the evidence of peri-epicardial LGE associated or not with pericardial effusion [22]. These findings may be attributed to fibrosis and/or edema due to an ongoing active pericarditis after infection resolution, which may constitute the basis for clinical sequelae in the short and long term. Table 2 reports the main studies evaluating the association of COVID-19 and pericardial diseases published until March 2021. Past medical history, presenting symptoms, ECG, echocardiographic findings, troponin level, and outcome are detailed for each study. In most patients, pericardial disease was associated with myocardial involvement, as documented by troponin elevation, and in a high percentage of cases (12/ $25,48 \%)$ pericardial effusion complicated by cardiac tamponade was described. Only one 


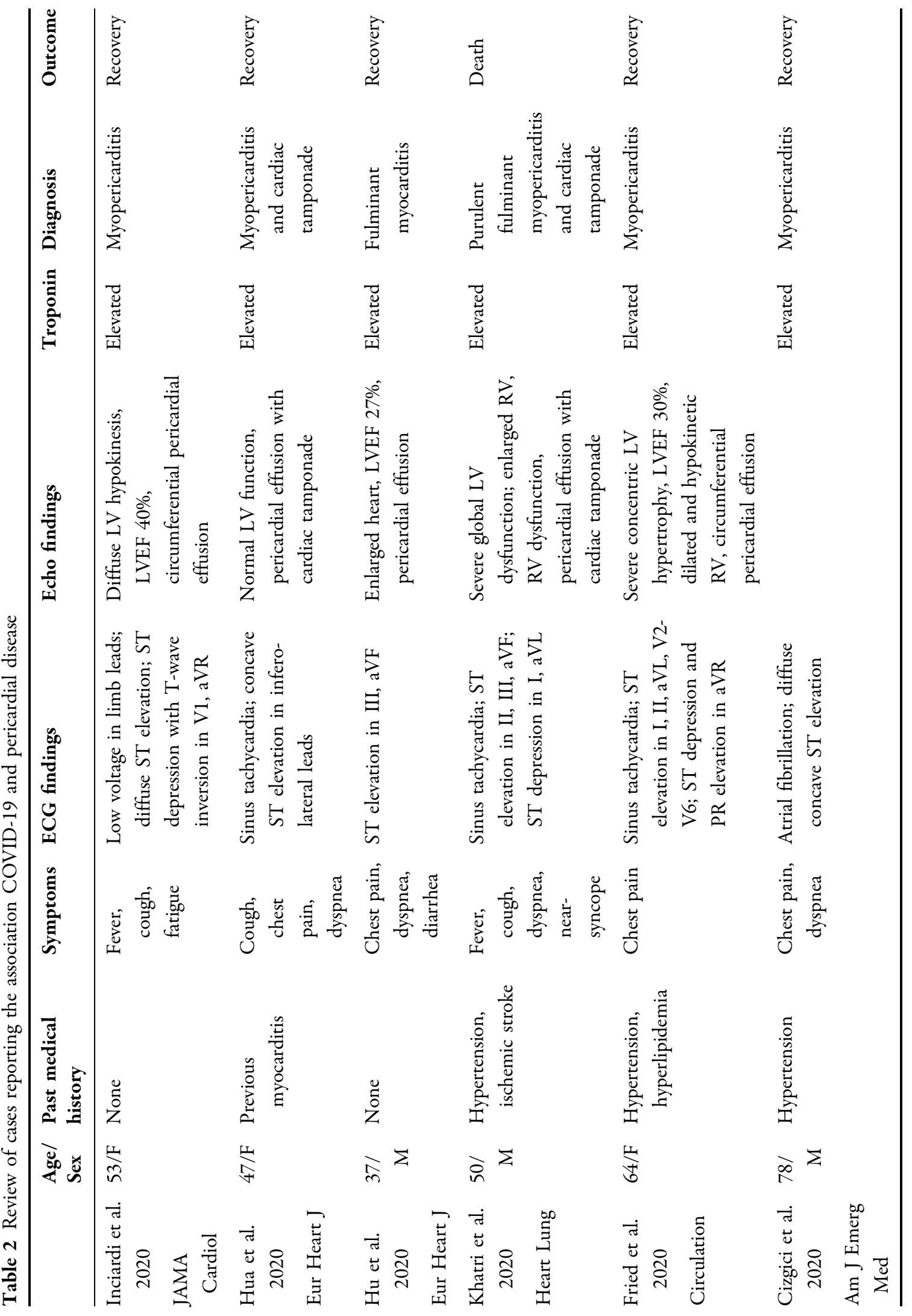




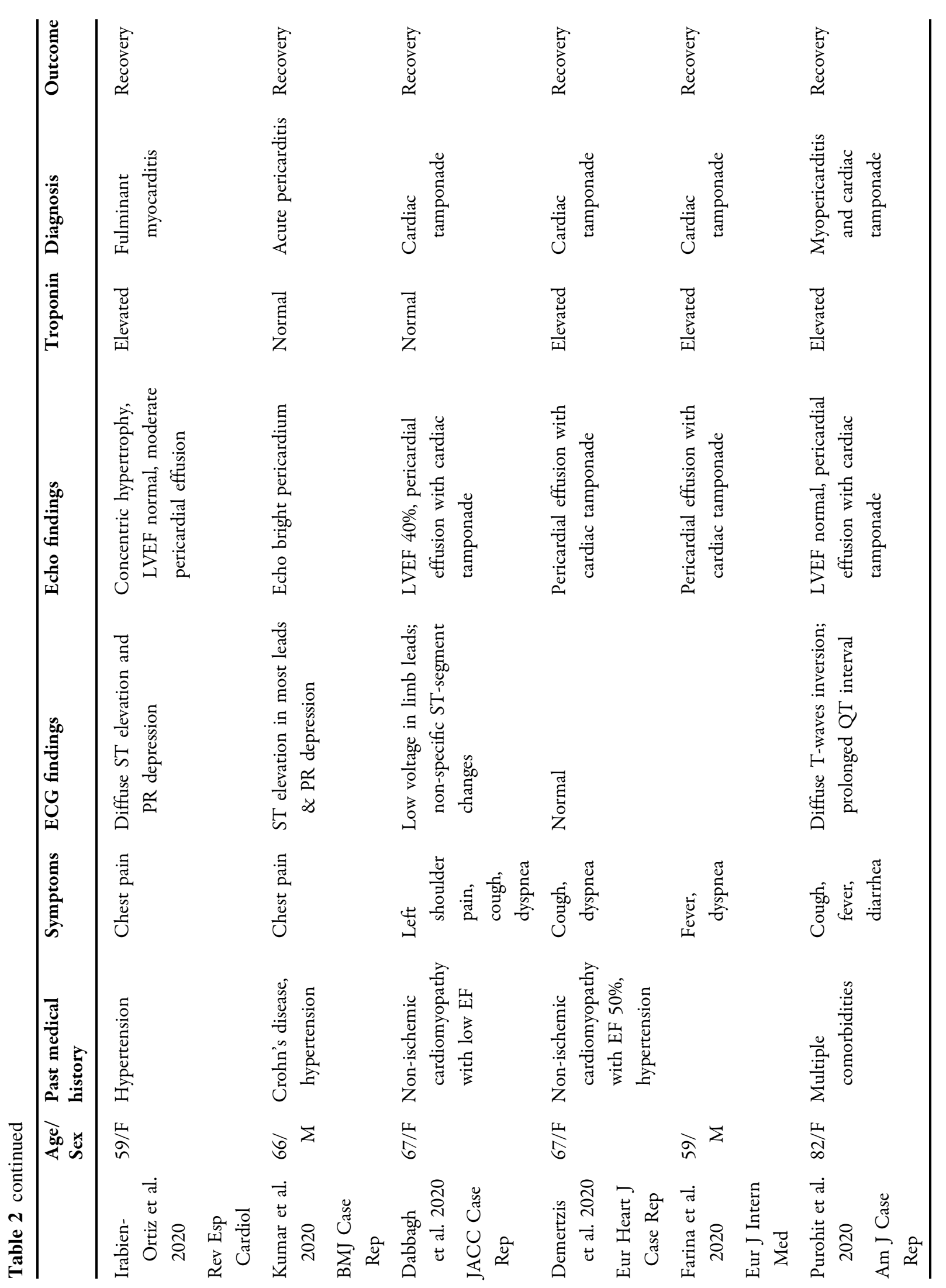




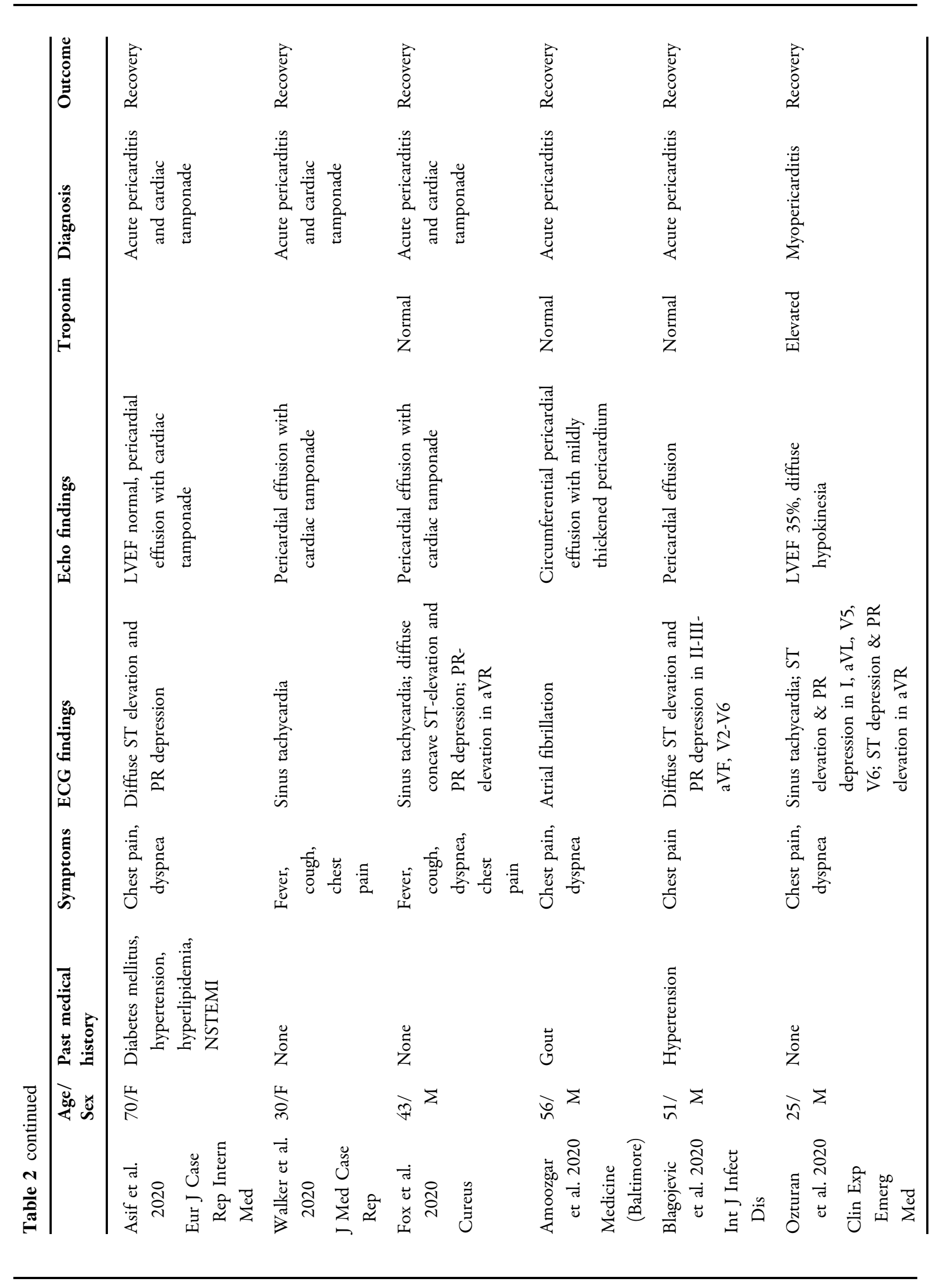




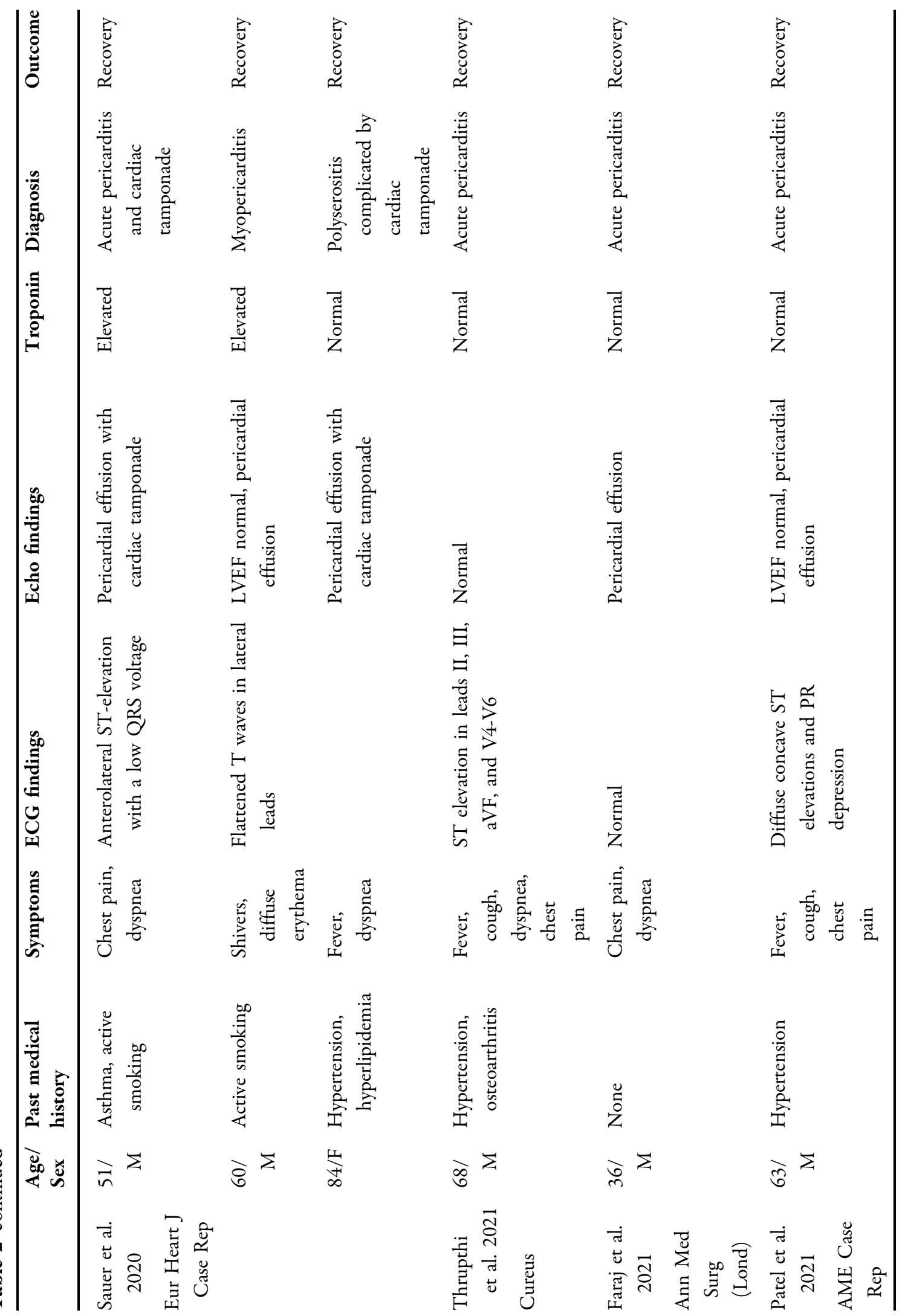




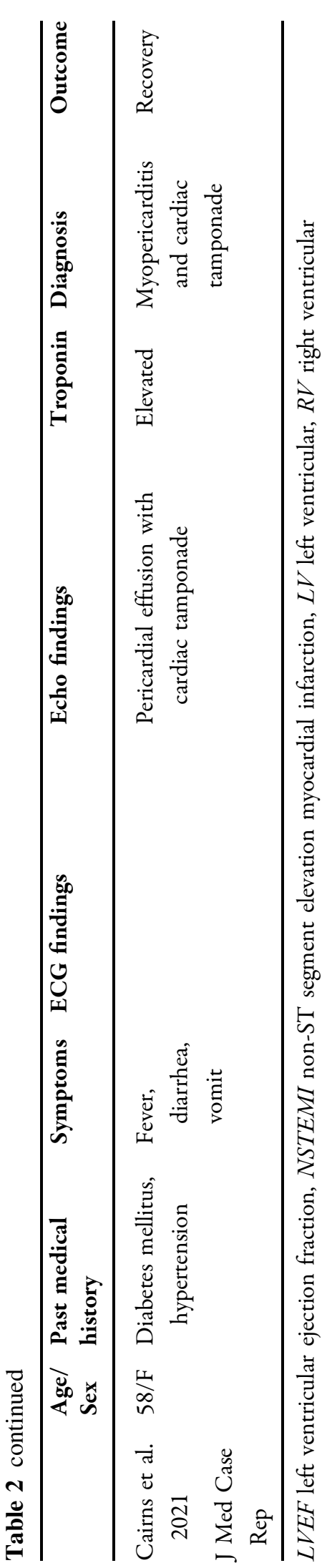

death occurred, and that outcome data were limited to the hospitalization period. Follow-up data were unavailable for all the studies.

To date, it is unknown whether pericarditis recurrence or a constrictive pathology may occur after months of COVID-19 recovery. Appropriate clinical and instrumental follow-up of these patients should be considered based on clinical judgement.

\section{Venous Thromboembolism}

Venous thromboembolism (VTE), which includes deep vein thrombosis (DVT) and pulmonary embolism (PE), is very common in patients with SARS-CoV-2 infection. VTE has been reported in approximately $27 \%$ of critically ill patients hospitalized with COVID-19 [67]. This high incidence, particularly for PE, is significantly higher than previously reported in critically ill patients with pneumonia caused by other viruses, including H1N1 pneumonia and severe acute respiratory syndrome [68]. Also, the rate of VTE in hospitalized patients with COVID-19 and acute respiratory distress syndrome (ARDS) has been reported to be two- to ten-fold higher than those with ARDS secondary to other etiologies. VTE has been occasionally reported also in COVID-19 patients with mild symptoms [69].

Patients with PE and COVID-19 showed a higher risk of death independently from other indicators of disease severity, such as older age, LV systolic dysfunction, ARDS, and cardiac injury [70]. In these patients, the increased RV afterload and the high pulmonary arterial pressures led to RV dysfunction and, subsequently, to a worse outcome [71]. Indeed, RV dysfunction emerged as one of the principal determinants of early mortality during the acute phase, particularly in the presence of preexisting chronic right HF conditions [72].

Interestingly, in patients that have recovered from COVID-19, persistent RV involvement has been reported at a median of 74 days after discharge [73]. Impaired RV longitudinal strain was found in $42 \%$ of cases and resulted significantly lower compared to controls. This finding was confirmed in a prospective observational 
single-center analysis that reported, in patients recovered from moderate and severe COVID-19 pneumonia, subclinical RV dysfunction at 30 days after discharge, as suggested by lower tricuspid annular plane systolic motion (TAPSE), RV fractional area change and RV free wall strain [74]. However, these studies lack dedicated analysis on the long-term effects of RV function in patients with VTE during hospitalization.

COVID-19 is associated with coagulopathy characterized by mild thrombocytopenia, high levels of D-dimer, and fibrinogen degradation products, slight prolongation of the prothrombin time, and elevated levels of fibrinogen and factor VIII [75]. Although the drivers of this coagulopathy are uncertain, other proposed mechanisms of VTE are endothelial dysfunction, inflammation, hypoxemia, as well as an increase in platelet activation and aggregation [76]. Russo et al. have investigated the clinical impact of antithrombotic therapy at admission in patients hospitalized with COVID-19, demonstrating that neither antiplatelet therapy nor anticoagulant therapy may reduce the risk for ARDS and death in severe forms of SARSCoV-2 infection [77].

Antithrombotic therapy in COVID-19 is an active area of investigation, with multiple ongoing randomized clinical trials evaluating a variety of regimens with antiplatelet, anticoagulant, or their combinations. Antiplatelet and anticoagulant agents have well-documented anti-inflammatory and antithrombotic effects and may deserve a remarkable role in the setting of COVID-related endothelial injury and thrombo-inflammation [78, 79]. However, the selection of the proper antithrombotic regimen in COVID-19 patients is an open clinical issue. Controversial data remain on what is the best anticoagulant agent and on the optimal dosing; in the meantime, the current evidence seems to suggest a careful assessment of ischemic and bleeding risk, tailored to the individual patient.

The paucity of DVT in COVID-19 patients with PE may suggest that in many cases an in situ mechanism of thrombosis rather than an embolic one is involved. This mechanism is supported by a recent case series of autopsy reports, which found an unusually high degree of microthrombi in the lung arteries in the context of a thrombotic microangiopathic process [80]. Interestingly, in patients that died of COVID-19, multiple thrombi were found not only in the vessels of the lungs but also in those of the liver, heart, and kidneys. Nonetheless, in hospitalized patients with COVID-19, asymptomatic DVT was also observed, suggesting that emboli from lower extremities may also contribute to the burden of PE [81]. In the paper of Vlachou et al., PE episodes were observed up to 4 weeks after COVID-19 recovery, frequently not associated with significant lung involvement [82]. This highlights that thrombotic risk in the pulmonary vasculature may persist after hospital discharge. In a small cohort of COVID19 patients and PE observed at 3-month followup, recurrent VTE was reported in only $1.6 \%$ of cases, similar to that reported for the general VTE population at short term [83, 84]. Moreover, a high prevalence (30\%) of residual thrombosis at computed tomography pulmonary angiogram was found, albeit in the absence of chronic thromboembolic pulmonary hypertension. Conversely, Demelo-Rodrìguez et al. found no VTE recurrence among 100 patients at long-term follow-up (90 days or more) from diagnosis of COVID-19 and VTE [85]. However, larger ongoing prospective studies (e.g., CORONA-VTE, CISCO-19, and CORE-19) will help to establish more definitive rates of such complications.

Another important issue is the type and the duration of thromboprophylaxis after the acute phase. The estimation of the thrombotic and hemorrhagic risk remains fundamental, especially after the discharge from the hospital, in order to extend thromboprophylaxis for the patients with elevated risk of recurrent VTE and acceptable bleeding risk [76].

In the absence of evidence from large perspective studies, case-by-case considerations should orient the choice in clinical practice for these patients [86]. This topic is currently under investigations by several active randomized clinical trials [(NCT04508439, COVID-PREVENT (NCT04416048), ACTIV4 (NCT04498273), and PREVENT-HD (NCT04508023)]. 


\section{FUTURE PERSPECTIVES AND CONCLUSIONS}

COVID-19 is a novel disease, and many uncertainties remain regarding its potential longterm sequelae.

In patients that have recovered from COVID19 , it is plausible that myocardial injury may be the initiator of an inflammatory cascade, edema, and subsequent fibrosis. The extent and distribution of ongoing inflammation may be the basis for adverse ventricular remodeling and malignant arrhythmias.

Patients with clinical, laboratory, or imaging evidence of cardiac involvement during the acute phase may be at higher risk to develop further complications and death due to $\mathrm{CV}$ causes.

After infection resolution, residual subclinical disease deserves attention and should be investigated with second-level CV imaging modalities. Particularly, the use of CMR has the potential to improve the current knowledge on subclinical myocardial damage and ongoing inflammatory process after the acute phase.

Although not available in every center and difficult to routinely use in all patients recovered from COVID-19, CMR should be considered in those with high probability of cardiovascular sequelae. CMR should complement the diagnostic work-up in patients with persisting signs and/or symptoms suggestive for cardiac involvement, in those with unexplained reduction of LV EF or pericardial effusion by transthoracic echocardiography, and in those who developed myocardial injury during the acute phase.

Although recovery from COVID-19 is generally reported within 12 weeks, the time required for full recovery may vary for each individual. All patients who experienced COVID-19 should be informed about the most common symptoms following the acute phase, and a screening questionnaire may help in detecting those with ongoing or new-onset symptoms suggestive for cardiovascular sequelae after the disease resolution. Clinical and instrumental assessment including ECG, laboratory testing, and firstlevel cardiac imaging are warranted in these patients to detect persistent or new signs of cardiac damage and define tailored follow-up strategies.

Despite no dedicated guidelines on professional athletes and highly physically active adults are available, ECG, high-sensitivity troponin testing, and echocardiography have been indicated by consensus. This is particularly important for subjects who develop new cardiovascular symptoms after return to play or before return to play and, in any case, in all subjects who experienced moderate-to-severe forms of COVID-19 or required hospitalization [64] CMR should be considered, as second-level investigation, in case of abnormal testing in order to confirm and characterize the nature and extension of cardiac damage.

To date, it is unknown whether the severity of cardiac injury, the type of treatments adopted during the acute phase, the hemodynamic response, or other host factors may influence long-term outcome. Large registries, longer follow-up, and randomized clinical trials should be intended to answer the open questions on the "post-COVID-19 cardiac syndrome".

An etiological diagnosis of myocardial injury during the hospitalization is the first step for an appropriate follow-up of COVID-19 patients with cardiovascular involvement. After discharge, the screening for residual left and right ventricular dysfunction, arrhythmias, residual thrombosis, and myocardial scar should be considered on a case-by-case basis, whereas an active clinical surveillance is mandatory in any case.

\section{ACKNOWLEDGEMENTS}

Compliance with Ethics Guidelines. This article is based on previously conducted studies and does not contain any new studies with human participants or animals performed by any of the authors.

Funding. No Rapid Service Fee was received by the journal for the publication of this article. 
Authorship. All named authors meet the International Committee of Medical Journal Editors (ICMJE) criteria for authorship for this article, take responsibility for the integrity of the work as a whole, and have given their approval for this version to be published.

Author Contributions. Concept and design: Silverio A, Polito MV. First drafting the manuscript: Silverio A, Polito MV, Bellino M, Iuliano G, Di Maio M, Alfano C, Iannece P. Final approval of manuscript: Galasso G, Esposito N.

Disclosures. Maria Vincenza Polito, Angelo Silverio, Michele Bellino, Giuseppe Iuliano, Marco Di Maio, Carmine Alfano, Patrizia Iannece, Nicolino Esposito, and Gennaro Galasso have nothing to disclose.

Data Availability. Data sharing is not applicable to this article as no datasets were generated or analyzed during the current study.

Open Access. This article is licensed under a Creative Commons Attribution-NonCommercial 4.0 International License, which permits any non-commercial use, sharing, adaptation, distribution and reproduction in any medium or format, as long as you give appropriate credit to the original author(s) and the source, provide a link to the Creative Commons licence, and indicate if changes were made. The images or other third party material in this article are included in the article's Creative Commons licence, unless indicated otherwise in a credit line to the material. If material is not included in the article's Creative Commons licence and your intended use is not permitted by statutory regulation or exceeds the permitted use, you will need to obtain permission directly from the copyright holder. To view a copy of this licence, visit http://creativecommons.org/licenses/by$\mathrm{nc} / 4.0 /$.

\section{REFERENCES}

1. Epidemiology Working Group for Ncip Epidemic Response CCfDC, Prevention. The epidemiological characteristics of an outbreak of 2019 novel coronavirus diseases (COVID-19) in China. Zhonghua Liu Xing Bing Xue Za Zhi. 2020;41(2):145-51.

2. Silverio A, Di Maio M, Ciccarelli M, Carrizzo A, Vecchione C, Galasso G. Timing of national lockdown and mortality in COVID-19: the Italian experience. Int J Infect Dis. 2020;100:193-5.

3. Yang X, Yu Y, Xu J, Shu H, Xia J, Liu H, et al. Clinical course and outcomes of critically ill patients with SARS-CoV-2 pneumonia in Wuhan, China: a single-centered, retrospective, observational study. Lancet Respir Med. 2020;8(5):475-81.

4. Zhang H, Penninger JM, Li Y, Zhong N, Slutsky AS. Angiotensin-converting enzyme 2 (ACE2) as a SARS-CoV-2 receptor: molecular mechanisms and potential therapeutic target. Intensive Care Med. 2020;46(4):586-90.

5. Chen L, Li X, Chen M, Feng Y, Xiong C. The ACE2 expression in human heart indicates new potential mechanism of heart injury among patients infected with SARS-CoV-2. Cardiovasc Res. 2020;116(6): 1097-100.

6. Zhou F, Yu T, Du R, Fan G, Liu Y, Liu Z, et al. Clinical course and risk factors for mortality of adult inpatients with COVID-19 in Wuhan, China: a retrospective cohort study. Lancet. 2020;395(10229):1054-62.

7. Silverio A, Di Maio M, Citro R, Esposito L, Iuliano G, Bellino $\mathrm{M}$, et al. Cardiovascular risk factors and mortality in hospitalized patients with COVID-19: systematic review and meta-analysis of 45 studies and 18,300 patients. BMC Cardiovasc Disord. 2021;21(1):23.

8. Russo V, Silverio A, Scudiero F, Micco PD, Maio MD. Pre-admission atrial fibrillation in COVID-19 patients: prevalence and clinical impact. Eur J Intern Med. 2021;88:133-5.

9. National Institute for Health and Care Excellence: Clinical Guidelines. COVID-19 rapid guideline: managing the long-term effects of COVID-19. London: National Institute for Health and Care Excellence (UK); 2020.

10. Nalbandian A, Sehgal K, Gupta A, Madhavan MV, McGroder C, Stevens JS, et al. Post-acute COVID-19 syndrome. Nat Med. 2021;27(4):601-15.

11. Carfì A, Bernabei R, Landi F. Persistent symptoms in patients after acute COVID-19. JAMA. 2020;324(6): 603-5.

12. Corrales-Medina VF, Alvarez KN, Weissfeld LA, Angus DC, Chirinos JA, Chang CC, et al. Association between hospitalization for pneumonia and 
subsequent risk of cardiovascular disease. JAMA. 2015;313(3):264-74.

13. Corrales-Medina VF, Musher DM, Shachkina S, Chirinos JA. Acute pneumonia and the cardiovascular system. Lancet. 2013;381(9865):496-505.

14. Ayoubkhani D, Khunti K, Nafilyan V, Maddox T, Humberstone B, Diamond I, et al. Post-covid syndrome in individuals admitted to hospital with covid-19: retrospective cohort study. BMJ. 2021;372:n693.

15. Thygesen K, Alpert JS, Jaffe AS, Chaitman BR, Bax JJ, Morrow DA, et al. Fourth universal definition of myocardial infarction (2018). J Am Coll Cardiol. 2018;72(18):2231-64.

16. Lala A, Johnson KW, Januzzi JL, Russak AJ, Paranjpe I, Richter F, et al. Prevalence and impact of myocardial injury in patients hospitalized with COVID-19 infection. J Am Coll Cardiol. 2020;76(5): 533-46.

17. Giustino G, Croft LB, Stefanini GG, Bragato R, Silbiger JJ, Vicenzi $M$, et al. Characterization of myocardial injury in patients with COVID-19. J Am Coll Cardiol. 2020;76(18):2043-55.

18. Shi S, Qin M, Shen B, Cai Y, Liu T, Yang F, et al. Association of cardiac injury with mortality in hospitalized patients with COVID-19 in Wuhan. China JAMA Cardiol. 2020;5(7):802-10.

19. Yang C, Liu F, Liu W, Cao G, Liu J, Huang S, et al. Myocardial injury and risk factors for mortality in patients with COVID-19 pneumonia. Int J Cardiol. 2021;326:230-6.

20. Hendren NS, Drazner MH, Bozkurt B, Cooper LT Jr. Description and proposed management of the acute COVID-19 cardiovascular syndrome. Circulation. 2020;141(23):1903-14.

21. Li R, Wang H, Ma F, Cui GL, Peng LY, Li CZ, et al. Widespread myocardial dysfunction in COVID-19 patients detected by myocardial strain imaging using 2-D speckle-tracking echocardiography. Acta Pharmacol Sin. 2021. https://doi.org/10.1038/ s41401-020-00595-z.

22. Puntmann VO, Carerj ML, Wieters I, Fahim M, Arendt C, Hoffmann J, et al. Outcomes of cardiovascular magnetic resonance imaging in patients recently recovered from Coronavirus disease 2019 (COVID-19). JAMA Cardiol. 2020;5(11):1265-73.

23. Chapman AR, Shah ASV, Lee KK, Anand A, Francis $\mathrm{O}$, Adamson $\mathrm{P}$, et al. Long-term outcomes in patients with type 2 myocardial infarction and myocardial injury. Circulation. 2018;137(12): $1236-45$
24. Polito MV, Hagendorff A, Citro R, Prota C, Silverio A, De Angelis E, et al. Loeffler's endocarditis: an integrated multimodality approach. J Am Soc Echocardiogr. 2020;33(12):1427-41.

25. Silverio A, Citro R, Nardi F. Clinical imaging in patients experiencing chest pain. Minerva Cardioangiol. 2017;65(6):601-15.

26. Citro R, Pontone G, Pace L, Zito C, Silverio A, Bossone $\mathrm{E}$, et al. Contemporary Imaging in Takotsubo syndrome. Heart Fail Clin. 2016;12(4):559-75.

27. Kotecha T, Knight DS, Razvi Y, Kumar K, Vimalesvaran K, Thornton G, et al. Patterns of myocardial injury in recovered troponin-positive COVID19 patients assessed by cardiovascular magnetic resonance. Eur Heart J. 2021;42:1866-78.

28. Citro R, Pontone G, Bellino M, Silverio A, Iuliano G, Baggiano A, et al. Role of multimodality imaging in evaluation of cardiovascular involvement in COVID-19. Trends Cardiovasc Med. 2021;31(1): 8-16.

29. Libby P, Tabas I, Fredman G, Fisher EA. Inflammation and its resolution as determinants of acute coronary syndromes. Circ Res. 2014;114(12): 1867-79.

30. Rivero F, Antuña P, Cuesta J, Alfonso F. Severe coronary spasm in a COVID-19 patient. Catheter Cardiovasc Interv. 2021;97(5):E670-2.

31. Courand PY, Harbaoui B, Bonnet M, Lantelme P. Spontaneous coronary artery dissection in a patient with COVID-19. JACC Cardiovasc Interv. 2020;13(12):e107-8.

32. Bangalore S, Sharma A, Slotwiner A, Yatskar L, Harari R, Shah B, et al. ST-segment elevation in patients with COVID-19: a case series. N Engl J Med. 2020;382(25):2478-80.

33. Stefanini GG, Montorfano $M$, Trabattoni D, Andreini D, Ferrante G, Ancona M, et al. ST-elevation myocardial infarction in patients with COVID19: clinical and angiographic outcomes. Circulation. 2020;141(25):2113-6.

34. Garcia S, Albaghdadi MS, Meraj PM, Schmidt C, Garberich R, Jaffer FA, et al. Reduction in ST-segment elevation cardiac catheterization laboratory activations in the United States during COVID-19 pandemic. J Am Coll Cardiol. 2020;75(22):2871-2.

35. Piccolo R, Bruzzese D, Mauro C, Aloia A, Baldi C, Boccalatte $M$, et al. Population trends in rates of percutaneous coronary revascularization for acute coronary syndromes associated with the COVID-19 outbreak. Circulation. 2020;141(24):2035-7. 
36. Pessoa-Amorim G, Camm CF, Gajendragadkar P, De Maria GL, Arsac C, Laroche C, et al. Admission of patients with STEMI since the outbreak of the COVID-19 pandemic: a survey by the European Society of Cardiology. Eur Heart J Qual Care Clin Outcomes. 2020;6(3):210-6.

37. De Luca G, Verdoia M, Cercek M, Jensen LO, Vavlukis M, Calmac L, et al. Impact of COVID-19 pandemic on mechanical reperfusion for patients with STEMI. J Am Coll Cardiol. 2020;76(20): 2321-30.

38. Baldi E, Sechi GM, Mare C, Canevari F, Brancaglione A, Primi R, et al. Out-of-hospital cardiac arrest during the Covid-19 outbreak in Italy. N Engl J Med. 2020;383(5):496-8.

39. Moroni F, Gramegna M, Ajello S, Beneduce A, Baldetti L, Vilca LM, et al. Collateral damage: medical care avoidance behavior among patients with myocardial infarction during the COVID-19 pandemic. JACC Case Rep. 2020;2(10):1620-4.

40. Pilato E, Pinna GB, Parisi V, Manzo R, Comentale G. Mechanical complications of myocardial infarction during COVID-19 pandemic: an Italian single-centre experience. Heart Lung. 2020;49(6):779-82.

41. Rimac G, Marzouk M, Dumont É, Paradis JM. When a delayed cardiology consultation leads to a massive left ventricle pseudoaneurysm: collateral effects of the COVID-19 pandemic. Eur Heart J. 2020;41(32): 3102 .

42. Peretto G, Sala S, Caforio ALP. Acute myocardial injury, MINOCA, or myocarditis? Improving characterization of coronavirus-associated myocardial involvement. Eur Heart J. 2020;41(22):2124-5.

43. Caforio AL, Pankuweit S, Arbustini E, Basso C, Gimeno-Blanes J, Felix SB, et al. Current state of knowledge on aetiology, diagnosis, management, and therapy of myocarditis: a position statement of the European Society of Cardiology Working Group on Myocardial and Pericardial Diseases. Eur Heart J. 2013;34(33):2636-48.

44. Polito MV, Ravera A. Myocarditis in the era of SARSCoV-2: one piece of a complex puzzle? Herz. 2020;45(5):458-60.

45. Kawakami R, Sakamoto A, Kawai K, Gianatti A, Pellegrini D, Nasr A, et al. Pathological evidence for SARS-CoV-2 as a cause of myocarditis: JACC review topic of the week. J Am Coll Cardiol. 2021;77(3): 314-25.

46. Imazio $\mathrm{M}$, Klingel $\mathrm{K}$, Kindermann I, Brucato A, De Rosa FG, Adler Y, et al. COVID-19 pandemic and troponin: indirect myocardial injury, myocardial inflammation or myocarditis? Heart. 2020;106(15): 1127-31.

47. Kariyanna PT, Sutarjono B, Grewal E, Singh KP, Aurora L, Smith L, et al. A systematic review of COVID-19 and myocarditis. Am J Med Case Rep. 2020;8(9):299-305.

48. Sawalha K, Abozenah M, Kadado AJ, Battisha A, AlAkchar M, Salerno C, et al. Systematic review of COVID-19 related myocarditis: insights on management and outcome. Cardiovasc Revasc Med. 2021;23:107-13.

49. Ho JS, Sia CH, Chan MY, Lin W, Wong RC. Coronavirus-induced myocarditis: a meta-summary of cases. Heart Lung. 2020;49(6):681-5.

50. Lindner D, Fitzek A, Bräuninger H, Aleshcheva G, Edler C, Meissner K, et al. Association of cardiac infection with SARS-CoV-2 in confirmed COVID-19 autopsy cases. JAMA Cardiol. 2020;5(11):1281-5.

51. Herskowitz A, Campbell S, Deckers J, Kasper EK, Boehmer J, Hadian D, et al. Demographic features and prevalence of idiopathic myocarditis in patients undergoing endomyocardial biopsy. Am J Cardiol. 1993;71(11):982-6.

52. Peretto G, Sala S, Rizzo S, Palmisano A, Esposito A, De Cobelli $F$, et al. Ventricular arrhythmias in myocarditis: characterization and relationships with myocardial inflammation. J Am Coll Cardiol. 2020;75(9):1046-57.

53. Grün S, Schumm J, Greulich S, Wagner A, Schneider $\mathrm{S}$, Bruder $\mathrm{O}$, et al. Long-term follow-up of biopsyproven viral myocarditis: predictors of mortality and incomplete recovery. J Am Coll Cardiol. 2012;59(18):1604-15.

54. Gräni C, Eichhorn C, Bière L, Murthy VL, Agarwal $\mathrm{V}$, Kaneko K, et al. Prognostic value of cardiac magnetic resonance tissue characterization in risk stratifying patients with suspected myocarditis. J Am Coll Cardiol. 2017;70(16):1964-76.

55. Aquaro GD, Ghebru Habtemicael Y, Camastra G, Monti L, Dellegrottaglie S, Moro C, et al. Prognostic value of repeating cardiac magnetic resonance in patients with acute myocarditis. J Am Coll Cardiol. 2019;74(20):2439-48.

56. Russo V, Di Maio M, Mottola FF, Pagnano G, Attena $\mathrm{E}$, Verde N, et al. Clinical characteristics and prognosis of hospitalized COVID-19 patients with incident sustained tachyarrhythmias: A multicenter observational study. Eur J Clin Invest. 2020;50(12): e13387.

57. Huang L, Zhao P, Tang D, Zhu T, Han R, Zhan C, et al. Cardiac involvement in patients recovered 
from COVID-2019 identified using magnetic resonance imaging. JACC Cardiovasc Imaging. 2020;13(11):2330-9.

58. Phelan D, Kim JH, Chung EH. A game plan for the resumption of sport and exercise after Coronavirus disease 2019 (COVID-19) infection. JAMA Cardiol. 2020;5(10):1085-6.

59. Schellhorn P, Klingel K, Burgstahler C. Return to sports after COVID-19 infection. Eur Heart J. 2020;41(46):4382-4.

60. Baggish A, Drezner JA, Kim J, Martinez M, Prutkin JM. Resurgence of sport in the wake of COVID-19: cardiac considerations in competitive athletes. $\mathrm{Br} \mathrm{J}$ Sports Med. 2020;54(19):1130-1.

61. Rajpal S, Tong MS, Borchers J, Zareba KM, Obarski $\mathrm{TP}$, Simonetti OP, et al. Cardiovascular magnetic resonance findings in competitive athletes recovering from COVID-19 infection. JAMA Cardiol. 2021;6(1):116-8.

62. Pelliccia A, Solberg EE, Papadakis M, Adami PE, Biffi A, Caselli S, et al. Recommendations for participation in competitive and leisure time sport in athletes with cardiomyopathies, myocarditis, and pericarditis: position statement of the Sport Cardiology Section of the European Association of Preventive Cardiology (EAPC). Eur Heart J. 2019;40(1):19-33.

63. Maron BJ, Udelson JE, Bonow RO, Nishimura RA, Ackerman MJ, Estes NAM 3rd, et al. Eligibility and disqualification recommendations for competitive athletes with cardiovascular abnormalities: task force 3: hypertrophic cardiomyopathy, arrhythmogenic right ventricular cardiomyopathy and other cardiomyopathies, and myocarditis: a scientific statement from the American Heart Association and American College of Cardiology. J Am Coll Cardiol. 2015;66(21):2362-71.

64. Phelan D, Kim JH, Elliott MD, Wasfy MM, Cremer P, Johri AM, et al. Screening of potential cardiac involvement in competitive athletes recovering from COVID-19: an expert consensus statement. JACC Cardiovasc Imaging. 2020;13(12):2635-52.

65. Sauer F, Dagrenat C, Couppie P, Jochum G, Leddet $P$. Pericardial effusion in patients with COVID-19: case series. Eur Heart J Case Rep. 2020;4(Fi1):1-7.

66. Esposito A, Palmisano A, Natale L, Ligabue G, Peretto $\mathrm{G}$, Lovato L, et al. Cardiac magnetic resonance characterization of myocarditis-like acute cardiac syndrome in COVID-19. JACC Cardiovasc Imaging. 2020;13(11):2462-5.

67. Beun R, Kusadasi N, Sikma M, Westerink J, Huisman A. Thromboembolic events and apparent heparin resistance in patients infected with SARSCoV-2. Int J Lab Hematol. 2020;42(Suppl 1):19-20.

68. Obi AT, Tignanelli CJ, Jacobs BN, Arya S, Park PK, Wakefield TW, et al. Empirical systemic anticoagulation is associated with decreased venous thromboembolism in critically ill influenza A H1N1 acute respiratory distress syndrome patients. J Vasc Surg Venous Lymphat Disord. 2019;7(3):317-24.

69. Fiorini NB, Garagoli F, Bustamante RC, Pizarro R (2021) Acute pulmonary embolism in a patient with mild COVID-19 symptoms: a case report. Eur Heart J Case Rep 5(1): 63. **

70. Scudiero F, Silverio A, Di Maio M, Russo V, Citro R, Personeni D, et al. Pulmonary embolism in COVID19 patients: prevalence, predictors and clinical outcome. Thromb Res. 2021;198:34-9.

71. Pagnesi M, Baldetti L, Beneduce A, Calvo F, Gramegna $M$, Pazzanese $V$, et al. Pulmonary hypertension and right ventricular involvement in hospitalised patients with COVID-19. Heart. 2020;106(17):1324-31.

72. Park JF, Banerjee S, Umar S. In the eye of the storm: the right ventricle in COVID-19. Pulm Circ. 2020;10(3):2045894020936660.

73. Nuzzi V, Castrichini M, Collini V, Roman-Pognuz E, Di Bella S, Luzzati R, et al. Impaired right ventricular longitudinal strain without pulmonary hypertension in patients who have recovered from COVID-19. Circ Cardiovasc Imaging. 2021;14(4): 2166.

74. Günay N, Demiröz Ö, Kahyaoğlu M, Başlılar Ş, Aydın M, Özer M, et al. The effect of moderate and severe COVID-19 pneumonia on short-term right ventricular functions: a prospective observational single pandemic center analysis. Int J Cardiovasc Imaging. 2021. https://doi.org/10.1007/s10554021-02171-w.

75. Tang N, Li D, Wang X, Sun Z. Abnormal coagulation parameters are associated with poor prognosis in patients with novel coronavirus pneumonia. J Thromb Haemost. 2020;18(4):844-7.

76. Bikdeli B, Madhavan MV, Jimenez D, Chuich T, Dreyfus I, Driggin E, et al. COVID-19 and thrombotic or thromboembolic disease: implications for prevention, antithrombotic therapy, and follow-up: JACC sew. J Am Coll Cardiol. 2020;75(23):2950-73.

77. Russo V, Di Maio M, Attena E, Silverio A, Scudiero F, Celentani D, et al. Clinical impact of pre-admission antithrombotic therapy in hospitalized patients with COVID-19: A multicenter observational study. Pharmacol Res. 2020;159:104965. 
78. Zarbock A, Polanowska-Grabowska RK, Ley K. Platelet-neutrophil-interactions: linking hemostasis and inflammation. Blood Rev. 2007;21(2):99-111.

79. Li X, Zheng Z, Li X, Ma X. Unfractionated heparin inhibits lipopolysaccharide-induced inflammatory response through blocking p38 MAPK and NF- $\kappa B$ activation on endothelial cell. Cytokine. 2012;60(1):114-21.

80. Ackermann M, Verleden SE, Kuehnel M, Haverich A, Welte $T$, Laenger $F$, et al. Pulmonary vascular endothelialitis, thrombosis, and angiogenesis in Covid-19. N Engl J Med. 2020;383(2):120-8.

81. Demelo-Rodríguez P, Cervilla-Muñoz E, OrdieresOrtega L, Parra-Virto A, Toledano-Macías M, Toledo-Samaniego $\mathrm{N}$, et al. Incidence of asymptomatic deep vein thrombosis in patients with COVID-19 pneumonia and elevated D-dimer levels. Thromb Res. 2020;192:23-6.

82. Vlachou M, Drebes A, Candilio L, Weeraman D, Mir N, Murch N, et al. Pulmonary thrombosis in Covid19: before, during and after hospital admission. J Thromb Thrombolysis. 2021. https://doi.org/10. 1007/s11239-020-02370-7.
83. Whyte MB, Barker R, Kelly PA, Gonzalez E, Czuprynska J, Patel RK, et al. Three-month followup of pulmonary embolism in patients with COVID-19. Thromb Res. 2021;201:113-5.

84. Werth S, Kamvissi V, Stange T, Kuhlisch E, Weiss N, Beyer-Westendorf J. Outpatient or inpatient treatment for acute pulmonary embolism: a retrospective cohort study of 439 consecutive patients. J Thromb thrombolysis. 2015;40(1):26-36.

85. Demelo-Rodríguez P, Ordieres-Ortega L, Ji Z, Del Toro-Cervera J, de Miguel-Díez J, Álvarez-Sala-Walther LA, et al. Long-term follow-up of patients with venous thromboembolism and COVID-19: Analysis of risk factors for death and major bleeding. Eur J Haematol. 2021;106(5):716-23.

86. Spyropoulos AC, Levy JH, Ageno W, Connors JM, Hunt BJ, Iba T, et al. Scientific and Standardization Committee communication: clinical guidance on the diagnosis, prevention, and treatment of venous thromboembolism in hospitalized patients with COVID-19. J Thromb Haemost. 2020;18(8): 1859-65. 